\title{
Refletindo sobre a tensão entre pesquisa e prática: o caso do ensino de ciências
}

\author{
Reflecting about the tension between research and practice: the case \\ of science teaching
}

Talita Vidal Pereira*

Universidade do Estado do Rio de Janeiro

Resumo Nesse artigo a ideia de que os resultados das pesquisas em educação não são incorporados adequadamente na formulação de políticas educacionais é problematizada a partir de argumentos desenvolvidos em uma perspectiva pós-estruturalista e pós-colonial. Esses argumentos tomam como objeto de análise as produções das comunidades disciplinares que pesquisam o ensino de ciências com a compreensão de que elas expressam discursos que circulam nos diferentes contextos de produção curricular. A análise rompe com a distinção entre conhecimento e cultura e passa a assumi-los como processo de enunciação de sentidos. Interessa discutir como as concepções dos pesquisadores sobre o conhecimento e as práticas docentes são informadas por um realismo epistemológico que fundamenta a dimensão transformadora que é atribuída ao conhecimento, cuja apropriação é significada como possibilidade de emancipação.

PALAVRAS-CHAVE: Ensino de ciências; Currículo; Cultura; Conhecimento.

Abstract In this article the idea that the research results in education are not adequately incorporated in the formulation of educational policy is questioned from some developed arguments in a poststructuralist and postcolonial perspective. These arguments take as analysis object the disciplinary community products that research science education, with the understanding that these express discourses, which are circulating in different curricular contexts. The analysis breaks the distinction between knowledge and culture and takes them as a process of sense enunciation. The focus is discussing how the researchers' conceptions about knowledge and teaching practices are informed by an epistemological realism that justifies the processing dimension attributed to knowledge, whose ownership is meant as a possibility of emancipation. KEYWORDS: Teaching of science; Curriculum; Culture; Knowledge. 


\section{Introduzindo...}

Neste artigo, são desenvolvidos argumentos para questionar a ideia de que os resultados das pesquisas em educação não são incorporados adequadamente na formulação de políticas educacionais e que isso corrobora para a existência de um profundo abismo entre uma produção teórica sofisticada, resultado do investimento na pesquisa em educação, e a prática cotidiana nas escolas (MOREIRA, 1998; SOUZA, 1993). Para problematizar essa compreensão, são articulados argumentos que se sustentam na compreensão de realidade como processo de produção discursiva, conforme propõe as abordagens pós-estruturalistas. Referenciais que oferecem contribuições importantes para que possamos refletir sobre as expectativas criadas sobre a possibilidade de a pesquisa acadêmica produzir, de forma linear, mudanças nas escolas na direção desejada pelos formuladores das políticas e/ou pelos pesquisadores. No texto, essas expectativas são entendidas como expressão de um realismo epistemológico, que sustenta e se sustenta em uma lógica do pensamento dicotômico que organiza o pensamento moderno e que, diante de um fenômeno social, tende a nos colocar perante duas alternativas excludentes entre si (VEIGA-NETO, 2008).

Os argumentos são desenvolvidos tomando como foco a análise das produções das comunidades disciplinares que pesquisam o ensino de Ciências, com a compreensão de que elas se constituem como discursos que circulam nos diferentes contextos de produção curricular. Nesta perspectiva, foram selecionadas nos anais dos Encontros Nacionais de Pesquisa em Educação Ciências (ENPEC), realizados bianu -almente entre 1997 e 2009, e com reflexões voltadas para o ensino de Ciências nos anos iniciais de escolaridade, ou seja, do primeiro ao quinto ano do Ensino Fundamental ${ }^{1}$.

Trata-se de uma leitura pós-estruturalista sobre produções do campo do ensino de ciências que, majoritariamente, adotam uma abordagem crítica, estruturalista. Dessa forma, trata-se de oferecer uma outra possibilidade de interpretar os fenômenos educacionais, assumindo que todas as alternativas de análise e de interpretação são sempre parciais e provisórias. Nessa perspectiva, sem desconsiderar as contribuições oferecidas por cada uma delas, o estudo tem por objetivo discutir os seus limites, principalmente se levarmos em conta a complexidade implicada nas formas de conceber as práticas pedagógicas, a pesquisa, o conhecimento e as possibilidades transformadoras atribuídas ao conhecimento implicadas nessas concepções.

\section{Uma leitura pós-estruturalista}

Segundo Lopes (2013), sob a designação de "pós” podemos identificar um conjunto de teorias que se caracterizam pela problematização das tentativas de fixar e controlar sentidos produzidos sobre o mundo. Tentativas que se ancoram em certezas e que tendem a remeter ao essencialismo da significação. Embora identificadas como pós, são diferentes abordagens com questões e problemáticas próprias. No entanto, compartilham princípios que nos permitem pensá-las, arbitrariamente, como "conjunto". O abandono dos axiomas essencialistas é um desses princípios, caro ao pensamento pós-estruturalista. No entanto, o pós-estruturalismo não deve ser entendido 
como uma ruptura com o estruturalismo, ao contrário, ambos "partilham uma postura antirrealista e anti-positivista, na medida em que entendem toda realidade como mediada pela linguagem". No entanto, "o pós-estruturalismo organiza-se em torno da crítica a Saussure pela defesa da flutuação de sentidos do significante" (LOPES, 2013, p. 12). Nessa perspectiva, trata-se de uma postura mais radical e que possibilita analisar rastros de realismo presentes nas análises estruturalistas. Uma postura que implica assumir a realidade como construção discursiva. $\mathrm{O}$ social como textualidade sujeito às arbitrariedades de sentidos atribuídos a um significante.

No estudo em questão, as produções analisadas são assumidas como discursos que produzem, e tentam fixar, sentidos sobre a escola. Tentativas de fixar aquilo que a instituição é e o que deveria ser, numa dinâmica que corrobora para colocar "em lados opostos os sujeitos que dominam os saberes considerados legítimos e os sujeitos que dominam os saberes deslegitimados" (LOPES; MACEDO, 2011, p. 93), reforçando a fronteira que separa nós dos outros.

É a partir desse entendimento que a ideia de escola como lócus da conservação de práticas descontextualizadas e de concepções superadas, que parece nos textos analisados de maneira mais ou menos explícita, é questionada. Essa percepção, resultado das expectativas estabelecidas a priori que sustentam as investigações e/ou avaliações realizadas na/ou sobre as escolas, tende a obstaculizar as possibilidades de apreensão do dinamismo característico de um espaço-tempo em que diferentes saberes circulam, negociam, mesclam-se e produzem sentidos (TURA, 2002).

São tentativas de fixação de sentidos que a Teoria do discurso, desenvolvida por Ernesto Laclau e Chantal Mouffe (2010), oferece subsídios importantes que possibilitam investigar como eles são produzidos pelas e nas pesquisas, como são negociados e traduzidos no campo das práticas e vice-versa, dado que as práticas escolares são objetos importantes na pesquisa educacional. Dessa forma, utilizando o discurso como categoria de análise, é possível investigar que sentidos de conhecimento e de educação estão sendo articulados nas enunciações educacionais, possibilitando que elas se afirmem como atos de poder. "Poder de significar, de criar sentidos e hegemonizá-los" (LOPES; MACEDO, 2011, p. 40). Poder de deslegitimar outros sentidos produzidos nas e sobre as escolas.

É importante destacar que, para Laclau e Mouffe (2010), discurso não se limita a fala e/ou ao texto. Os autores concebem discurso como prática de significação sem relação exclusiva ou primária com a fala ou a escrita.

Nessa abordagem discursiva, são problematizadas tanto a pretensão de o conhecimento acessar a realidade, como enfatizado pelas concepções realistas, quanto as concepções idealistas que enfatizam a dimensão subjetiva da apreensão da realidade.

Não há acesso imediato ao empírico, a alguma dimensão que poderíamos denominar realidade, pois toda mediação do empírico se desenvolve pela linguagem, toda interpretação e construção de ideias é um processo de representação que pressupõe as práticas nas quais essa mediação, interpretação ou construção estão situadas. Para além do discurso, há apenas o campo da discursividade. (LOPES; MACEDO; TURA, 2012, p. 120). 
Trata-se de assumir que em todos os espaços-tempo disputamos sentidos teóricos e práticos com os quais operamos no mundo. Dessa forma, os discursos produzidos sobre a escola são assumidos como resultado de processos de negociação de sentidos, que são permanentemente disputados e traduzidos nas escolas, na academia, nos encontros de especialistas, nos processos de formulações de políticas curriculares, enfim, na dinâmica discursiva. Portanto, a legitimidade conferida a determinados sentidos é resultado de uma operação discursiva que busca constituí-los como hegemônicos (LACLAU, 2006; 2011).

Outra problematização diz respeito à dimensão de originalidade e de pureza atribuída às diferentes formas de conhecer. $\mathrm{O}$ ato de conhecer implica produção de sentidos que nos permitem operar no mundo. Um processo discursivo pelo qual conferimos significado ao mundo e nele intervimos. Portanto, não existe nenhum fundamento a priori que justifique a distinção entre conhecimento e cultura, principalmente se considerarmos que essa diferenciação tende a hierarquizá-las, atribuindo status privilegiado ao conhecimento, em relação à cultura. Cultura entendida como processo de enunciação de significados sobre o mundo. O conhecimento também é produção de sentidos sobre o mundo. Não se trata de negar a materialidade do mundo, mas de assumir que é discursivamente que atribuímos sentidos a essa materialidade, o que, por sua vez, não acontece sem conflitos.

Bhabha (2007) oferece contribuições que possibilitam questionar a ideia de um conhecimento puro, produzido em um lócus específico, e reproduzido linearmente na escola a partir de um conjunto de práticas previamente planejadas, ou possibilitando a transformação de práticas estabelecidas se pensarmos nas propostas de formação docente. Como produção cultural, o conhecimento é concebido como híbrido, implicado em processos de negociação e tradução de sentidos que esvaziam qualquer pretensão de originalidade e pureza. $\mathrm{E}$, como processo de enunciação de sentidos, não há qualquer fundamento que justifique a pretensão de totalidade de uma determinada forma de conhecer, porque não há uma realidade que possa ser plenamente acessada. Tudo o que há são sentidos produzidos discursivamente e implicados em relações de poder, que nos possibilitam operar no mundo (LACLAU, 2011).

É recorrente a compreensão de que existe uma grande distância entre produção acadêmica e o cotidiano das escolas. Uma crítica similar costuma ser feita pelos gestores educacionais quando avaliam os resultados das políticas que pretendem implementar nas escolas. Neste artigo, essa percepção é analisada como resultado das expectativas a priori, que sustentam as investigações e/ou avaliações realizadas na/ou sobre as escolas. Nos dois casos, resguardados os diferentes posicionamentos teóricos, políticos e filosóficos, existe a expectativa de que a ação social se organiza em torno de um fundamento capaz de efetuar uma transformação radical da realidade (LACLAU, 2011).

Dessa forma, se existe, por parte dos pesquisadores do campo da educação, uma vasta produção que identifica e faz uma crítica radical ao estabelecimento de standards de desempenho que tem caracterizado as políticas curriculares, também é preciso reconhecer que as reflexões produzidas pelos pesquisadores não estão isentas 
de expectativas a priori sobre a possibilidade de a pesquisa acadêmica transformar radicalmente as práticas escolares.

$\mathrm{Na}$ comunidade de pesquisadores investigada, não acontece de forma diferente. Neles são desenvolvidos vários argumentos sobre a necessidade de mudanças no ensino de Ciências praticado nas escolas, para que esse se torne capaz de possibilitar aos alunos a apropriação dos conhecimentos científicos, apresentada como condição imperativa para a formação cidadã. Nesses discursos, a ideia de formação cidadã se aproxima da ideia de emancipação, e ao conhecimento é atribuída a capacidade de possibilitar, àqueles que dele se apropriam, o acesso à realidade do jeito que ela é e, dessa forma, nela intervir, transformando-a.

Leal e Gouvêa (1999, p. 4) justificam e defendem a necessidade de maiores investimentos em educação científica, afirmando a "apropriação do conhecimento científico como elemento importante na capacitação do sujeito para o pleno exercício de sua cidadania”. Pavan, Brasil e Terrazzan (2008, p. 4) afirmam que a alfabetização científica e tecnológica deve "oportunizar as pessoas, desde os anos iniciais na escola, uma relação dos conceitos dessa área do saber com a prática cotidiana" e que "deve primar pela transformação social do indivíduo" (Op. Cit). Por sua vez, Abreu et al (2008, p. 2) afirmam que a falta de domínio dos conteúdos científicos torna as pessoas "totalmente impotentes frente ao desafio de construir uma sociedade que preserve a qualidade de vida tanto individual quanto coletiva".

Maiores investimentos em educação científica desde os anos iniciais do Ensino Fundamental são requeridos dado que a apropriação dos conteúdos científicos, em uma perspectiva crítica, é apresentada como condição essencial para uma formação cidadã (AZEVEDO; GHENDIN; GONZAGA, 2008; MEGID NETO, 1999). Dessa forma, a associação entre apropriação dos conhecimentos científicos e a cidadania é o horizonte de verdade em que os pesquisadores vão inscrever suas propostas para o ensino de Ciências sem questionar as articulações que tornaram essa verdade uma possibilidade.

A formação das professoras dos anos iniciais é, via de regra, apontada como um obstáculo às inovações propostas pelo campo educacional, na medida em que não propiciam o esforço de reflexão necessário para que as professoras superem suas concepções inadequadas sobre a ciência e sobre o ensino (SILVA; MARCONDES, 2008) para que possam "transmitir" o conhecimento científico de forma que ele possa ser apropriado pelos alunos como instrumento de emancipação. Neste sentido, grande parte das pesquisas analisadas trabalham com o pressuposto de que os/as docentes possuem concepções equivocadas de ensino e de Ciências e a formação não tem sido suficiente para que eles as superem (ROCHA; MEGID NETO, 2009).

Entretanto, os discursos produzidos são carregados de ambiguidade. Neles uma perspectiva construtivista de conhecimento coexiste com uma abordagem prescritiva desenvolvida em grande parte delas. Cerca de 55\% dos 71 textos analisados durante a pesquisa propõem alguma alternativa metodológica para melhorar a qualidade do ensino de ciências. $O$ caráter prescritivo, ou propositivo em alguns casos, se justifica 
na medida em que os autores assumem como pressuposto a existência de um conjunto de performances mais adequadas que os processos de escolaridade devem contemplar no desenvolvimento de conteúdos apropriados. Pressupostos que reforçam "a concepção de uma cultura comum voltada para a formação de desempenhos adequados ao mercado ou ao contexto social mais amplo" (LOPES, 2006, p. 49), quando admitem a existência de um modelo de currículo capaz de dar conta da formação para contemplar esses desempenhos. Macedo (2012) destaca que essa compreensão de currículo justifica a centralidade do conhecimento nas definições curriculares e sustenta a vinculação entre currículo e ensino que, segundo a autora, cria obstáculos para que a diferença possa emergir no currículo.

Concordando com Macedo, é possível pensar que as expectativas, a priori, sobre os resultados das pesquisas na transformação da escola em uma direção definida como a mais adequada, também se constitui em obstáculo para que se possa apreender outras alternativas possíveis que emergem nesse espaço. Para que se possa apreender as diferenças sem, necessariamente, significá-las como equívocos ou inadequações.

A tendência prescritiva que aparece nos trabalhos analisados exemplifica as expectativas que os pesquisadores criam sobre as suas propostas para um melhor funcionamento da escola. Megid Neto (1999) e Pereira (2012) identificam essa tendência quando constatam que a pesquisa em ensino de Ciências tem sido predominantemente voltada para a dimensão metodológica do processo de ensino. Via de regra, os pesquisadores se propõem a desenvolver estudos em que procuram identificar os fatores que, segundo eles, obstaculizam a efetivação da proposta nas escolas, provocando o que compreendem como um descompasso, entre as concepções dos docentes sobre ciência e ensino. Para superar esse descompasso são apresentadas alternativas metodológicas e/ou formas de abordagens para o desenvolvimento de diferentes temáticas que podem ser utilizadas pelos professores (PEREIRA, 2012).

Mesmo em estudos que assumem uma perspectiva que procura compreender os fatores históricos e ideológicos que "contribuem para abafar as vozes dos professores em muros tradicionalistas que privilegiam a racionalidade técnica" (OLIVEIRA; DINIZ, 2008, p. 8), é recorrente a afirmação de que falta ao professor uma maior compreensão da teoria e/ou das propostas educacionais. Assim, mesmo reconhecendo que na ação pedagógica os conhecimentos são apropriados e ressignificados, as autoras continuam pensando o fazer docente em torno de questões tais como:

Por que o professor professa um discurso e realiza outra prática distante do seu discurso? O que o leva a agir assim? Será que esse discurso que ele professa sobre o ensino e suas finalidades é realmente dele? Ou será que historicamente esse professor apenas repete discursos que thes foram indicados pelos órgãos competentes como os mais corretos, de forma mecânica, mas, por não ser aquilo que ele realmente crê, sua prática é diferente de seu discurso? (OLIVEIRA, DINIZ, 2008, p. 2).

Aqui os processos de apropriação e ressignificação parecem ser admitidos desde que resultem em uma apreensão, por parte dos docentes, que as autoras jul- 
gam como as mais adequadas. Ou seja, persiste a ideia de um conhecimento capaz de melhor orientar o fazer pedagógico na formação do cidadão. Uma identidade fixa significada como a mais adaptada para atender às demandas do mundo contemporâneo. Como alerta Macedo (2012, p. 731), "as identidades que se pretende produzir via currículo assumem um caráter de meta (ou objetivo) para a consecução da qual concorrem todas as experiências escolares, mas, principalmente, aquelas mediadas pelos conteúdos". Essa expectativa tem fundamento na ideia de conhecimento como expressão de uma realidade que é aqui questionada a partir da compreensão de conhecimento como processo discursivo em que são atribuídos sentidos ao mundo, inclusive ao mundo material.

Também em estudos que propõem uma discussão sobre a natureza do conhecimento científico, sobre a sua historicidade social, como o realizado por Carvalho e Martins (2009), é recorrente a afirmação de que os professores em atuação nos anos iniciais apresentam "visões distorcidas da ciência" (p. 02). Distorção aqui compreendida como aquela que se desvia da real e que é caracterizada como expressão do senso comum, "marcada pela ideia de deturpação e de conhecimento menor" (LOPES; MACEDO; TURA, 2012, p. 116) e que desconsidera a especificidade do conhecimento escolar como discurso que produz sentidos para atender às "finalidades pedagógicas, sem que necessariamente essas novas finalidades possam ser consideradas negativas ou o conhecimento produzido possa ser considerado um erro ou uma deturpação" (LOPES; MACEDO, 2011, p. 106).

Nessa perspectiva, a ideia de deformação ou distorção apresentada pelos autores é problematizada na medida em que se sustentam no pressuposto de que existe uma realidade que pode ser apreendida em sua totalidade e de forma inequívoca e que existe um tipo de conhecimento capaz de possibilitar essa apreensão. Qualquer conhecimento diferente desse seria ilusório, pois não revelaria o funcionamento do mundo exatamente como ele é. As formas pelas quais o ensino, a escola e a prática dos professores são analisadas nesses discursos evidenciam a compreensão de que os conhecimentos produzidos pelas pesquisas se constituem como verdades sobre o ensino, a escola e a prática dos professores. É desse conhecimento que são formuladas propostas ou prescrições que visam alterar aquilo que é significado como inadequado.

Laclau (2000) faz considerações importantes para pensarmos essa questão. Segundo o autor, o pensamento ocidental moderno se orienta pelo pressuposto de que existe um fundamento último capaz de revelar o funcionamento do mundo e de que sua apreensão é condição para a emancipação. Dessa forma, a modernidade produziu diferentes teorizações sobre esse funcionamento, todas elas reivindicando o status de totalidade. Metanarrativas cuja a apropriação permitiria conhecer e intervir no mundo em uma direção significada discursivamente como a mais adequada.

Como alertam Wortmann e Veiga-Neto (2001, p. 41), é reforçada uma concepção realista que tem como pressuposto a existência de um mundo real/natural e "que a ciência se constitui no lugar privilegiado capaz de descrevê-lo, interpretá-lo, controlá-lo". Como se um conceito pudesse fixar o conteúdo de um enunciado, como se alguma coisa pudesse existir fora da linguagem e a verdade pudesse ser reificada. Mas 
se tudo o que temos são discursos em disputa pela significação daquilo que entendemos como social (LACLAU; MOUFFE, 2010), não há uma verdade a ser reificada. O que temos são tentativas de fixação necessárias para fazer valer determinados sentidos em detrimento de outros nas disputas por hegemonia. Trata-se, então, de constituir formas particulares de conceber a ação docente em um campo do conhecimento específico como padrões universais, portanto, passíveis de aplicação em qualquer contexto. O problema que aqui se apresenta é justamente sobre quem tem legitimidade para definir, de forma cabal e definitiva, o que seria considerado uma formação adequada. Trata-se de uma disputa por significados sem um fundamento a priori que possa legitimá-los. No entanto, em nome de uma hegemonia precária e contingente, são estabelecidas hierarquias arbitrárias que tendem a deslegitimar as apropriações singulares, os processos de tradução cultural (BHABHA, 2007), e com isso deixam de ser consideradas as relações diferenciais que emergem nos contatos que os professores têm com as propostas que chegam à escola e as inúmeras experiências de formação que não se limitam aos espaços formais, tudo em nome de uma lógica totalitária que sustenta a ideia de que é possível "ensinar tudo a todos, na crença do tudo poder dizer para formar o sujeito que se deseja", desconsiderando as situações contingentes em que o fazer pedagógico se realiza. Um fazer que "é acontecimento, é alteridade, é negociável, é contingente, reconhece os imprevistos” (MACEDO; PONTES; AXER, 2012, p. 2), marcado por trocas e negociações entre demandas diferenciais e provisórias.

Trata-se de assumir os processos de difusão do conhecimento como fluxos em negociações e traduções que possibilitam a formação de híbridos culturais (BHABHA, 2007). Essa compreensão implica romper com a lógica que "retira a ciência do campo do cultural e do social" (SILVA, 2000, p. 72). Uma fronteira que é justificada pela dimensão de universalidade atribuída à ciência, conhecimento, ao mesmo tempo em que significa a cultura como particularidade, the conferindo uma dimensão de relatividade.

No entanto, ao problematizar a dicotomia estabelecida entre o universal e o particular, Laclau (2011) nos oferece elementos para questionar as fronteiras que procuram demarcar a universalidade atribuída ao conhecimento e o relativismo atribuído à cultura. $\mathrm{O}$ autor concebe particular e universal como mutuamente referenciados. $\mathrm{Ou}$ seja, aquilo que é apresentado como universal, para ser assumido como tal, precisa carregar sentidos particulares. E vice-versa.

Pereira (2012) destaca que o processo de hegemonização do discurso científico, que possibilitou que ele seja apreendido como universal, é uma operação discursiva em que a demarcação de fronteiras entre ciência e saberes narrativos são tentativas de fixar diferenças, negando aos últimos o status de conhecimento legítimo.

No entanto, a veracidade atribuída aos enunciados da ciência só pode ser atestada dentro da lógica do jogo de linguagem em que se deu a sua produção (LYOTARD, 1986). Ou seja, os critérios para estabelecer essa diferenciação são próprios de uma pragmática que é própria de um saber particular, o científico. Laclau (2011) alerta que o reconhecimento de um determinado particular como universal não pode acontecer com o total abandono dos seus conteúdos particulares iniciais. Só é possível definir o verdadeiro em oposição a algo que é significado como falso. Por algo que a verdade não é. 
Com o entendimento de conhecimento como produção cultural, passamos a refletir sobre as implicações de assumir a cultura como entre-lugar deslizante sem qualquer compromisso com essencialismos ou originalidade. Reflexão que se justifica na indagação sobre a possibilidade da linguagem da teoria se constituir como "um estratagema da elite ocidental culturalmente privilegiada para produzir um discurso do Outro que reforça sua própria equação conhecimento-poder" (BHABHA, 2007, p. 45). Equação que está implicada nos discursos dos pesquisadores em nome de um ensino de ciências inscrito em um horizonte de valor e de verdade.

Nos textos estudados, esse horizonte pode ser identificado nos discursos que afirmam o conhecimento como construção histórica e social ou pela sua performance que lhe garantiria o status de regime de verdade como definido por Foucault (1980). Os autores descrevem um cenário de transformações científicas e tecnológicas que, segundo eles, justificaria maiores investimentos no ensino de ciências.

Sem negar a importância e o impacto da ciência e da tecnologia no mundo contemporâneo, é preciso problematizar essa crença "exacerbada com relação à evolução tecnológica, quase sempre desconectada de suas implicações de caráter social e humano" (BAZZO, 1998, p. 50). Por outro lado, também é preciso problematizar a associação apressada entre formação cidadã e apropriação dos conteúdos escolarizados. Macedo (2008) alerta que a luta por cidadania também se desenvolve a partir de movimentos sociais de sujeitos não-escolarizados e questiona essa associação que, segundo ela, pressupõe uma cidadania cujo exercício é deslocado para o futuro, o que contraria a ideia de uma cidadania exercida ativa e cotidianamente.

O cidadão e o não cidadão são constituídos na lógica dos binarismos que estão implicados em relações de poder que legitimam ou deslegitimam as diferenças.

$\mathrm{Na}$ perspectiva de romper com essa lógica, Bhabha (2007) opera com os conceitos de negociação e tradução. Conceitos que, na perspectiva do autor, carregam uma dimensão de temporalidade que não comporta oposições simplistas entre falso e verdadeiro, entre certo ou errado. Oposições que implicam, em alguma medida, algum tipo de essencialismo. Em Bhabha, a ideia de negociação expressa o esforço de tentar compreender como elementos antagônicos se articulam em relações ambivalentes, evitando explicações que buscam fundamento em uma racionalidade redentora que, operando por binarismos, acaba por negar as diferenças. E, no estudo em questão, acaba por constituir, em última análise, o docente como um não cidadão.

Pensar cultura como fluxo, como movimento de negociação e tradução sem que novos sentidos sejam produzidos, implica romper com a ideia de sentidos originais. Aquilo que nos habituamos a pensar como cultura original é produção incessante de sentidos que temos a pretensão de captar como em uma fotografia instantânea (APPPADURAI, 2001), mas que não se deixa aprisionar, que escapa e continua se produzindo sem orientações a priori. Dentro de limites, mas limites que sempre podem ser rompidos.

Não há nenhuma unidade ou conjunto de sentidos plenamente fixados que definam um campo de conhecimento. A estabilidade alcançada por alguns desses 
sentidos é resultado de um processo permanente de constituição de hegemonia (LACLAU; MOUFFE, 2010). A cada leitura esses sentidos são reapropriados e significados de forma diferente. Isso implica que, para Bhabha (2007), não é possível pensar em reprodução cultural, o que há é sempre produção de sentidos que não são puros ou originais, mas constituem-se em híbridos culturais. Logo, não há possibilidade de reprodução das propostas de ensino formuladas pelos pesquisadores em uma perspectiva linear, conforme parece ser as expectativas dos mesmos ao analisar seus impactos na escola.

\section{Finalizando...}

Sem desconsiderar as críticas que as abordagens pós-estruturalistas sofrem por aqueles que insistem se tratar de posições nihilistas que põem em risco projetos políticos emancipatórios, como a escola, por exemplo, entendo que essas reflexões são importantes para pensarmos os limites e as possibilidades dos projetos emancipatórios modernos, sem desconsiderar que esses projetos nos constituíram como sujeitos localizados no tempo e no espaço. Concordando com Laclau (2000), é possível ver na crise da razão a possibilidade de radicalizar a crítica a toda forma de dominação que pode favorecer a emergência de projetos obstacularizados pelo que o autor identifica como "ditadura racionalista do Iluminismo", cujos sentidos ainda estão presentes, em maior ou menor grau, nas nossas formas de operar no mundo.

Essa reflexão de Laclau (2000) permite estabelecer uma tentativa de diálogo com aquelas produções que, no campo do currículo, têm procurado reintroduzir elementos de um discurso em favor de um tipo de conhecimento que constituiria o conteúdo de uma identidade de vanguarda: o Sujeito emancipado. O Cidadão. Sem que isso signifique abandonar a ideia de projetos emancipatórios que não se constituam como discursos que sufocam as possibilidades de emergência das diferenças. "Não uma diferença especifica que se estabelece entre dois ou mais idênticos, mas a diferença em si, o diferir que é próprio dos movimentos instituintes, das enunciações e da cultura" (MACEDO, 2012, p. 736).

Afirmar a ausência de qualquer fundamento que explique o funcionamento do social implica assumir a sua inteligibilidade, só podemos analisar os "efeitos de sociedade", ou de "realidade", produzidos por um discurso a posteriori. Dessa forma, trata-se de introduzir outras perspectivas de análise para investigar a escola em uma lógica que procura analisar as tentativas de fixação de sentidos produzidos nos processos de intervenção no cotidiano escolar e nas investigações realizadas sobre eles. Perspectivas que possibilitem questionamentos sobre os limites da razão, dos valores e ideais de transformação radical, bem como a noção de vanguarda cultural responsável pela condução da humanidade em direção a um mundo melhor, ou de uma escola melhor. 


\section{Referências}

ABREU, L. S.; et al. O desafio de formar professores das séries iniciais para ensinar ciências. In: Encontro Nacional de Pesquisa em Educação em Ciências, 6. 2007, Florianópolis. Anais. Florianópolis. Belo Horizonte: FAE/UFMG, 2008. 1 CD-ROM.

APPADURAI, A. Dislocación y diferencia en la economia cultural global. Public Culture, 2 (2), p. 41-61, 2001. Disponível em: <http://www.cholonautas.edu.pe/modulos/biblioteca2.php?IdDocumento=0289>. Acesso em: 24. mar. 2008.

AZEVEDO, R. O.; GHENDIN, E.; GONZAGA, A. Conceitos teórico-epistemológicos na formação de professores para o ensino de ciências nos anos iniciais do ensino fundamental In: Encontro Nacional de Pesquisa em Educação em Ciências, 6, 2007, Florianópolis. Anais. Florianópolis. Belo Horizonte: FAE/UFMG, 2008. 1 CD-ROM.

BAZZO, W. Ciência, tecnologia e sociedade e o contexto da educação tecnológica. Florianópolis: UFSC, 1998.

BHABHA, H. O local da cultura. 4. reimp. Belo Horizonte: UFMG, 2007.

CARVALHO, L. dos S.; MARTINS, A. F. História da ciência na formação de professores das séries iniciais: uma proposta com quadrinhos. In: Encontro Nacional de Pesquisa em Educação em Ciências, 7, 2009, Florianópolis. Anais. Disponível em: <http://www.foco.fae.ufmg.br/viienpec/index.php/enpec/viienpec/paper/viewFile/455/619>. Acesso em: 6. fev. 2010.

FOUCAULT, M. La verdad y Las formas jurídicas. Barcelona: Gedisa, 1980.

LACLAU, E. Nuevas reflexiones sobre La revolucion de nuestro tiempo. 2 ed. Buenos Aires: Nueva Visión, 2000.

. Misticismo, retórica y política. Buenos Aires: Fondo de Cultura Económica, 2006.

. Emancipação e diferença. Rio de Janeiro: EdUERJ, 2011.

; MOUFFE, C. Hegemonía y estrategia socialista. Hacia una radicalización de la democracia. Buenos Aires, Fondo de Cultura Económica, 2010.

LEAL, M. C.; GOUVÊA, G. Ensino de Ciências e Ciência Tecnologia e Sociedade: comparando perspectivas no ensino formal e não-formal. In: Encontro Nacional de Pesquisa em Educação em Ciências, 2, 1999, Valinhos: Anais. Florianópolis: OPM CED/UFSC, 1999. 1 CD-ROM.

LOPES, A. C. Discursos nas políticas de currículo. Currículo sem Fronteiras, v. 6, n. 2, p. 33-52, jul./dez., 2006. Disponível em: <http://www.curriculosemfronteiras.org/vol6iss2articles/lopes. pdf >. Acesso em: 20. mai. 2008. p. $7-23$.

.Teorias pós-críticas, política e currículo. Educação, Sociedade e Culturas, n. 39, 2013,

LOPES, A. C. ; MACEDO, E. Teorias de currículo. São Paulo: Cortez, 2011.

LOPES, A. C. ; MACEDO, E.; TURA, M. de L. R. As Representações sociais e os estudos de política de currículo para formação docente. In: PLACCO, V. M. N de S.; VILLAS BÔAS, L.; SOUSA, C. (Org.). Representações sociais: diálogos com a Educação. Curitiba: Champagnat/ EDPUCPR, 2012, p. 109-136.

LYOTARD, J. O pós-moderno. 2. ed. Rio de Janeiro: José Olympio, 1986.

MACEDO, E. Políticas de currículo no cotidiano escolar. In: LOPES, A.C. et al (Orgs.). Políticas educativas e dinâmicas curriculares no Brasil e em Portugal. Petrópolis: DP et alii; Rio de Janeiro: FAPERJ, 2008, p. 139-165. 
MACEDO, E. Currículo e conhecimento: aproximações entre educação e ensino. Cadernos de Pesquisa.v. 42, n. 147, p. 700-715 set./dez., 2012. Disponível em: < http://educa.fcc.org.br/pdf/ cp/v42n147/v42n147a03.pdf>. Acesso em: 13 jan. 2013.

MACEDO, E.; PONTES, C.; AXER, B. Educação e ensino responsável. Disponível em: <http://www.fe.unicamp.br/gtcurriculoanped/35RA/trabalhos/TE-Anped2012-Educ_ensino_responsavel.pdf>.Acesso em: 20 abr. 2013.

MEGID NETO, J. O que sabemos sobre a pesquisa em ensino de Ciências no nível fundamental: tendências de teses e dissertações defendidas entre 1972 e 1995 . In: Encontro Nacional de Pesquisa em Educação em Ciências, 2, 1999, Valinhos: Anais. Florianópolis: OPM CED/ UFSC, 1999. 1 CD-ROM.

MOREIRA, A. F. B. Didática e currículo: questionando fronteiras. In: OLIVEIRA, M. R. (org.). Confluências e divergências entre didática e currículo, São Paulo: Papirus, 1998, p. 33-52.

OLIVEIRA, R. de; DINIZ, R. da S. O ensino de ciências nas séries iniciais do Ensino Fundamental: compreendendo discursos de professoras-alunas. In: Encontro Nacional de Pesquisa em Educação em Ciências, 7, 2009, Florianópolis. Anais. Disponível em: <http://www.foco.fae. ufmg.br/viienpec/index.php/enpec/viienpec/paper/viewFile/245/3>. Acesso em: 6. fev. 2010.

PAVAN, F.; BRASIL, J.; TERRAZZAN, E. O que se tem e o que se pode fazer com relação a alfabetização científica e tecnológica nos anos iniciais. In: Encontro Nacional de Pesquisa em Educação em Ciências, 6, 2007, Florianópolis. Anais. Belo Horizonte: FAE/UFMG, 2008. 1 CD-ROM.

PEREIRA, T. V. Analisando alternativas para o ensino de ciências naturais: uma abordagem pós-estruturalista. Rio de Janeiro: Quartet: Faperj, 2012.

ROCHA, M. B.; MEGID NETO, J. Práticas de formação de professores para o ensino de ciências nas séries iniciais do Ensino Fundamental. In: Encontro Nacional de Pesquisa em Educação em Ciências, Anais 7, Florianópolis, 2009. Disponível em: <http://www.foco.fae.ufmg.br/ viienpec/index.php/enpec/viienpec/paper/viewFile/1333/165>. Acesso em: 6 fev. 2010.

SILVA, A. de F. da; MARCONDES, M. E. Ensino e aprendizagem de ciências nas séries iniciais concepções de um grupo de professores em formação. In: Encontro Nacional de Pesquisa em Educação em Ciências, 6, 2007, Florianópolis. Anais. Florianópolis. Belo Horizonte: FAE/ UFMG, 2008. 1 CD-ROM.

SILVA, T. T. da. Currículo, universalismo e relativismo: uma discussão com Jean-Claude Forquin. Educação e Sociedade. v. 21, n. 73, p. 71-78, 2000. Disponível em: <http://www.scielo. $\mathrm{br} /$ scielo.php? script=sci_pdf\&pid=S0101-73302000000400005\&lng=pt\&nrm=iso\&tlng=pt $>$. Acesso em: 21 abr. 2009.

SOUZA, R. F. de. A produção intelectual brasileira sobre currículo a partir dos anos 80 . Em Aberto, (58): 117-128, 1993.

TURA, M. de L. R. Conhecimentos escolares e a circularidade entre culturas. In: LOPES, A. C.; MACEDO, E. (Orgs.). Currículo: debates contemporâneos. São Paulo: Cortez, 2002, p. 150-173.

VEIGA-NETO, A. Crise da modernidade e inovações curriculares: da disciplina para o controle. In: Sísifo. Revista de ciências da educação. Unidade de I\&D de Ciências da Educação da Universidade de Lisboa, n. 7, set./out./nov./dez., 2008, p. 141-150.

WORTMANN, M. L. C.; VEIGA-NETO, A. Estudos Culturais da Ciência e Educação. Belo Horizonte: Autêntica, 2001. 


\section{Notas}

${ }^{1}$ No contexto do estudo realizado no doutorado, interessava investigar se e como as especificidades desse nível de escolaridade são consideradas pelos pesquisadores em suas reflexões. Neste artigo, foram selecionados trabalhos apresentados em 1997, 1999, 2007 e 2009.

* Professora doutora da Universidade do Estado do Rio de Janeiro, Duque de Caxias, Rio de Janeiro, Brasil.

\section{Correspondência}

Talita Vidal Pereira - Universidade do Estado do Rio de Janeiro, Faculdade de Educação da Baixada Fluminense. Rua General Manoel Rabelo, s/n, Vila São Luís, CEP: 25065-970 - Duque de Caxias, Rio de Janeiro, Brasil.

E-mail: p.talitavidal@gmail.com

Recebido em 19 de julho de 2014

Aprovado em 17 de março de 2015 